\title{
Haemagglutination profiles of Helicobacter species that cause gastritis in man and animals
}

\author{
NANCY S. TAYLOR, ANNA T. HASUBSKI, J. G. FOX and A. LEE* \\ Division of Comparative Medicine, Massachusetts Institute of Technology, Cambridge, MA 02139, USA \\ and "School of Microbiology, University of New South Wales, Kensington, Sydney, Australia
}

\begin{abstract}
Summary. Thirty-five Helicobacter pylori isolates, $21 \mathrm{H}$. mustelae isolates and four strains of $H$. felis were compared for their ability to agglutinate red blood cells (RBCs). Isolates were examined in a slide haemagglutination assay with RBCs from 11 animal species, including rodents, carnivores and primates, as well as man. RBCs were agglutinated by $65-90 \%$ of $H$. mustelae isolates and $16-57 \%$ of $H$. pylori isolates. Treatment of $H$. mustelae with pronase and heat inhibited haemagglutination (HA) whereas heating only of $H$. pylori inhibited HA. Treatment of all strains of $H$. mustelae with trypsin inhibited agglutination of human RBCs; $75 \%$ of the treated strains did not agglutinate ferret RBCs. These results suggested that protein(s) may be important haemagglutinins for these bacteria. Variable HA profiles together with varying results after treatment of RBCs with fetuin, D-mannose, and neuraminidase suggested that multiple receptors may be involved in HA reactions with $H$. pylori and $H$. mustelae. The observation that $H$. mustelae and $H$. pylori agglutinated RBCs of several species and closely adhered to gastric epithelium supported the hypothesis that adherence plays a role in the colonisation and pathogenicity of $H$. mustelae and $H$. pylori. $H$. felis did not adhere to gastric epithelium and did not agglutinate RBCs of any species; nevertheless, $H$. felis can readily colonise and produce gastritis in several mammals.
\end{abstract}

\section{Introduction}

Helicobacter pylori is now firmly established as a causative agent of gastritis and, possibly, peptic ulcers in man. ${ }^{1,2} H$. pylori are seen adhered closely to gastric epithelium, between intracellular junctions and in the mucus layer of the stomach. ${ }^{3}$ Similarly, $H$. mustelae causes gastritis, and possibly ulcers, in the stomach and duodenum of ferrets; it adheres to the gastric epithelium and is endocytosed. ${ }^{4,5}$ Like $H$. pylori, the ferret gastric organisms are found in the mucus layer of the stomach. $H$. felis has been isolated from the stomachs of cats and dogs. ${ }^{6.7}$ An active, chronic gastritis in germ-free mice and rats, and chronic inflammation in gnotobiotic dogs has been produced by oral inoculation of $H$. felis. ${ }^{8-10}$ The acute inflammatory response seen in gnotobiotic rodents is similar to that described in the early stages of $H$. pylori infection. ${ }^{8,9}$

The observation that most bacterial adhesins are haemagglutinins is supported by the fact that bacterial adhesins share properties of moderate to strong hydrophobicity and the ability to recognise specific receptors. ${ }^{11,12}$ The chemical composition of the membranes of RBCs from various species differs and may give some clue to the receptor and adhesin necessary for bacterial adherence. For example, the sialic acid content is high in guinea-pig and human RBCs, whereas $\mathrm{O}$-acetyl derivatives of sialic acid are almost undetectable in RBCs of these species. ${ }^{13-16}$ In human RBCs, $95 \%$ of the sialic acid is present as $\mathrm{N}$-acetyl neuraminic acid. $^{15}$ Human RBCs also contain the binding receptor for the fimbrial adhesin of Escherichia coli J96. ${ }^{17}$ Sheep RBCs contain the Forssman antigen that is also a receptor for $E$. coli J96. ${ }^{17,18}$

Studies on haemagglutination (HA) profiles have suggested that adherence may be important in the colonisation and pathogenesis of $H$. pylori strains. ${ }^{19-21}$ Potential receptors for $H$. pylori have been purified and partially characterised; one is a glycerolipid, and another is $\mathrm{N}$-acetyl neuraminyl lactose receptor for the $H$. pylori fibrillae. ${ }^{19,21,22}$ If HA of RBCs is related to adherence and, possibly, virulence, $H$. mustelae, an organism with similar pathogenicity to $H$. pylori, should also agglutinate RBCs. Although $H$. felis can cause gastritis, it does not adhere to gastric epithelium and should not agglutinate RBCs. The aim of this study was to compare the HA activity of $H$.pylori with the HA patterns of newly recognised gastric Helicobacter spp. in animals and to relate this HA to colonisation in vivo. 


\section{Materials and methods}

\section{Bacterial strains}

All isolates were characterised as $H$. pylori, $H$. mustelae, or $H$. felis as described previously. ${ }^{1,2,4,6}$ Eleven $H$. pylori isolates were obtained from patients attending a gastroenterology clinic at Boston City Hospital. The other 24 isolates were obtained from the gastroenterology clinic at the Charity Hospital in New Orleans, LA. All $21 \mathrm{H}$. mustelae isolates were obtained from gastric biopsies of ferrets maintained in the Division of Comparative Medicine at Massachusetts Institute of Technology (MIT) over a 5-year period. $H$. felis type strain ATCC 49179 was obtained from a gastric biopsy of a cat at the University of New South Wales in Sydney, Australia. A further three strains of $H$. felis were obtained from stomachs of one cat and two dogs housed at the animal facility at the University of New South Wales.

\section{Bacterial cultures}

For the HA assay, H. mustelae and H. pylori were grown micro-aerophilically on Trypticase Soy Agar plates containing sheep blood $5 \%$ (Remel, Lenexa, $\mathrm{KA}$, USA) for $48-72 \mathrm{~h}$ at $37^{\circ} \mathrm{C}$. $\mathrm{H}$. felis was grown on Blood Agar Base No. 2 (Oxoid) plates containing lysed horse blood $5 \%$. The bacteria were harvested from the plates into phosphate-buffered saline (PBS) and washed three times with PBS. The suspension was adjusted spectrophotometrically $\left(\mathrm{OD}_{660}\right)$ to a density of $c .5 \times 10^{8}$ bacteria $/ \mathrm{ml}$.

\section{Red blood cells}

RBCs were obtained from various animal species housed at MIT. Group A and group B RBCs were obtained from human volunteers at the Division of Comparative Medicine. Blood was collected into heparinised tubes and centrifuged at $3000 \mathrm{rpm}$ (Damon/IEC centrifuge model CRV 5000) for $10 \mathrm{~min}$. RBCs were washed three times in PBS and used within 4 days of collection. $\mathrm{RBCs}$ were stored at $4^{\circ} \mathrm{C}$ at a concentration of $0.25 \% \mathrm{v} / \mathrm{v}$ in PBS.

\section{HA assay}

The HA assay was performed according to the method of Arthur et al. ${ }^{23}$ A $10-\mu$ l volume of $\mathrm{RBC}$ $0.25 \%$ suspension was thoroughly mixed with $10 \mu \mathrm{l}$ of bacterial suspension on a chilled glass slide. The slide was rotated at $60 \mathrm{rpm}$ for $10 \mathrm{~min}$ on a rotary platform (American Rotator V, American Dade, Miami, FA, USA). The assay was modified to read the slides microscopically for evidence of HA. Isolates that agglutinated RBCs were diluted serially two-fold to determine the titre.

\section{Inhibition assay}

The HA assay was performed with pre-treated bacteria and non-treated RBCs or with pre-treated
RBCs and non-treated bacteria. Bacteria were pretreated with pronase $0.02 \%$ or trypsin $0.025 \%$ at $37^{\circ} \mathrm{C}$ for $45 \mathrm{~min}$ before assay. Bacteria were also heated at $56^{\circ} \mathrm{C}$ for $45 \mathrm{~min}$ before assay. RBCs were pre-treated with fetuin $0.5 \mathrm{mg} / \mathrm{ml}$, neuraminidase $4.0 \mu \mathrm{g} / \mathrm{ml}$ or Dmannose $0.5 \%$ at $37^{\circ} \mathrm{C}$ for $1 \mathrm{~h}$ before assay. Trypsin was obtained from Whittaker MA Bioproducts, Walkersville, MD, pronase from Boheringer Mannheim, Indianapolis, IN, and fetuin, D-mannose and neuraminidase from Sigma Chemical Company, St Louis, MO, USA.

\section{Comparison of $H A$ assays}

HA assays were performed on 14 strains of $H$. pylori by the assays described above and by the assays described previously. ${ }^{19,20}$ For the slide assay, $10 \mu \mathrm{l}$ of RBCs $2 \% \mathrm{v} / \mathrm{v}$ suspension was mixed with $10 \mu \mathrm{l}$ of bacteria at c. $5 \times 10^{7}$ cells $/ \mathrm{ml}$ at room temperature. The assay was read visually after mixing for $1 \mathrm{~min} .{ }^{19}$ For the microtitration plate assay, $20 \mu$ l of RBCs $2 \%$ were added to $20 \mu$ l of bacteria in the microtitration wells and the mixture was incubated at $4^{\circ} \mathrm{C}$ overnight before the HA patterns were read. ${ }^{20}$ The assay was modified by adding bovine serum albumin (BSA), $1 \%$ $\mathrm{v} / \mathrm{v}$ to the buffer in an attempt to reduce false positive reactions.

\section{Results}

\section{HA assay}

Neither $H$. mustelae nor $H$. pylori uniformly agglutinated RBCs of any one species tested in the cold slide agglutination assay. Of the $21 \mathrm{H}$. mustelae strains, 66-90\%, and of the $35 \mathrm{H}$. pylori strains, $15-57 \%$, agglutinated the RBCs of the species tested (table I).

Table I. RBC HA patterns of (\%) $H$. pylori and $H$. mustelae isolates

\begin{tabular}{|c|c|c|}
\hline \multirow{2}{*}{ Source of RBCs } & \multicolumn{2}{|c|}{$\begin{array}{l}\text { Number (\%) of strains that } \\
\text { agglutinated RBCs }\end{array}$} \\
\hline & H. mustelae (21) & H. pylori (35) \\
\hline Man* & $19(90.5)$ & $10(28 \cdot 6)$ \\
\hline Rabbit & $16(76 \cdot 2)$ & $13(37 \cdot 1)$ \\
\hline Cat & $14(66 \cdot 7)$ & $7(20.0)$ \\
\hline Ferret & $15(71 \cdot 4)$ & $15(42.9)$ \\
\hline Macaca mulatta & $14(66 \cdot 7)$ & ND \\
\hline Dog & $14(66 \cdot 7)$ & ND \\
\hline Macaca fascicularis & $17(80 \cdot 1)$ & ND \\
\hline Sheep & $17(80 \cdot 1)$ & ND \\
\hline Guinea-pig & $18(85 \cdot 7)$ & ND \\
\hline Mouse & ND & $5(14 \cdot 3)$ \\
\hline Rat & ND & $15(42.9)$ \\
\hline Saimiri sciureus & ND & $20(57 \cdot 1)$ \\
\hline
\end{tabular}

H. felis did not agglutinate RBCs from any of the 12 species tested * Six strains (five $H$. pylori and one $H$. mustelae) were tested with human blood groups A and B. No difference in results was seen. ND $=$ not done. 

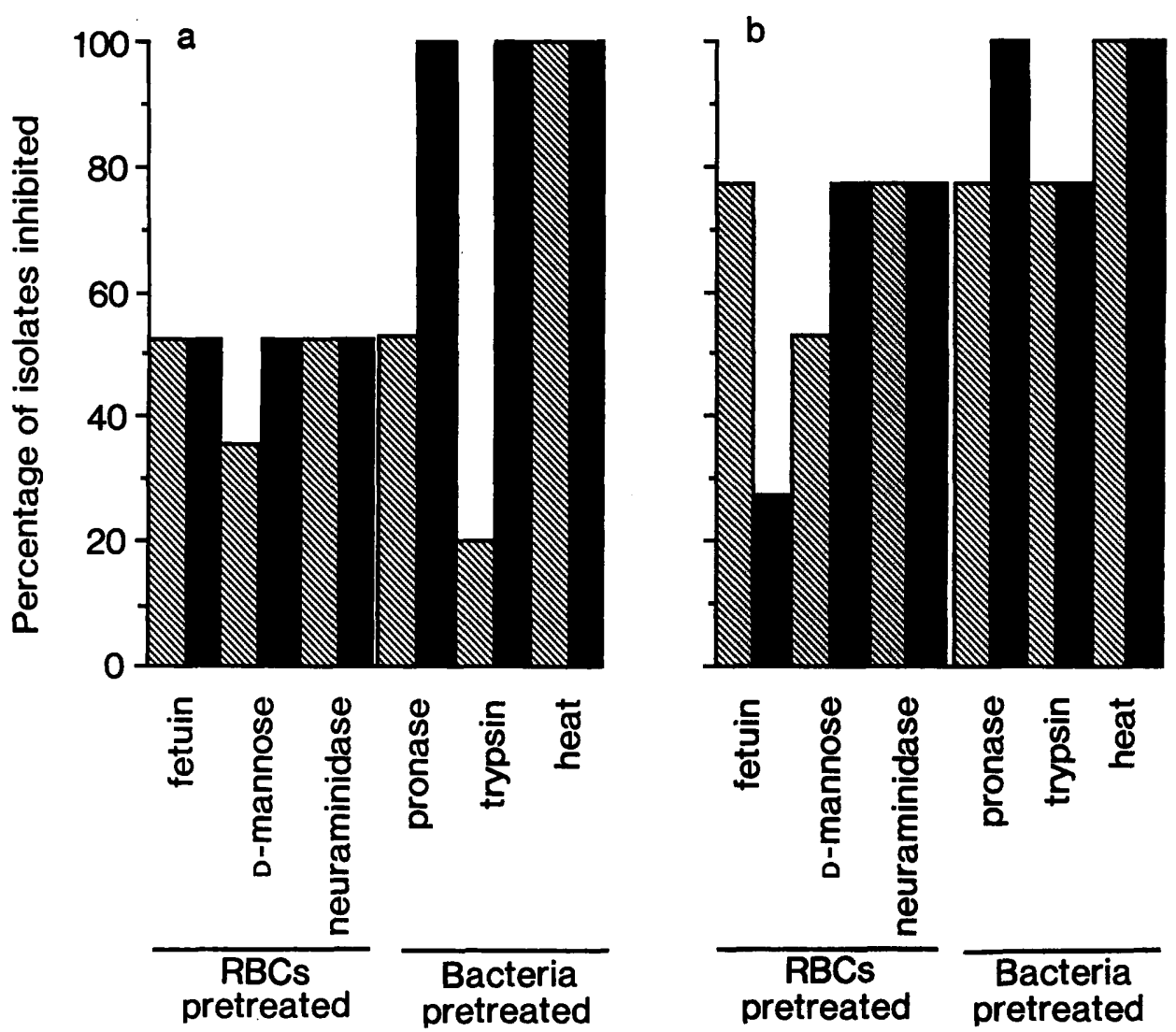

Figure. Inhibition by various treatments of agglutination of (a) human and (b) ferret red blood cells (RBCs) by $H$. pylori ( $\mathbb{S}$ ) and H. mustelae (西).

Table II. Comparison of HA assays

\begin{tabular}{llll|llll}
\hline $\begin{array}{c}\text { H. pylori } \\
\text { strain no. }\end{array}$ & $\begin{array}{c}\text { Origin of } \\
\text { RBCs }\end{array}$ & $\begin{array}{c}\text { Slide } \\
\text { assay }\end{array}$ & $\begin{array}{c}\text { Micro- } \\
\text { titration } \\
\text { assay }\end{array}$ & $\begin{array}{c}\text { H. pylori } \\
\text { strain no. }\end{array}$ & $\begin{array}{c}\text { Origin of } \\
\text { RBCs }\end{array}$ & $\begin{array}{c}\text { Slide } \\
\text { assay }\end{array}$ & $\begin{array}{c}\text { Micro- } \\
\text { titration } \\
\text { assay }\end{array}$ \\
\hline C125 & Cat & - & $-(-)$ & C057 & Cat & - & $-(-)$ \\
C140 & Cat & - & $-(-)$ & C057 & Mouse & - & $-(+)$ \\
C140 & Mouse & + & $+(+)$ & BU22 & Cat & - & $-(-)$ \\
C140 & Rabbit & - & $-(+)$ & BU22 & Mouse & - & $-(-)$ \\
C140 & Rat & + & $+(+)$ & BU22 & Rabbit & - & $-(-)$ \\
C140 & Man & + & $+(+)$ & BU22 & Rat & - & $-(-)$ \\
BU7 & Cat & - & $-(+)$ & BU22 & Man & - & $-(-)$ \\
BU7 & Mouse & - & $-(+)$ & BU14 & Cat & - & $-(+)$ \\
BU7 & Rabbit & + & $+(+)$ & BU14 & Mouse & + & $+(+)$ \\
BU7 & Rat & - & $-(+)$ & BU19 & Cat & - & $-(+)$ \\
CO77 & Cat & - & $-(+)$ & BU19 & Mouse & - & $-(+)$ \\
CO77 & Mouse & - & $-(+)$ & J19 & Cat & - & $-(+)$ \\
CO77 & Rabbit & - & $-(+)$ & CO59 & Cat & - & $-(-)$ \\
CO77 & Rat & - & $-(+)$ & J11 & Cat & + & $+(+)$ \\
C144 & Cat & - & $+(+)$ & J11 & Mouse & + & $+(+)$ \\
C144 & Mouse & - & $-(+)$ & J11 & Rabbit & + & $+(+)$ \\
CO16 & Cat & + & $+(+)$ & J11 & Rat & + & $+(+)$ \\
BU21 & Cat & - & $-(-)$ & J11 & Man & + & $+(+)$ \\
\hline
\end{tabular}

Results were obtained by microscopic reading $(100 \times)$ of slide assay and microtitration plate assay.

(). Results obtained by visual reading of the microtitration plate.

The highest HA titre obtained from all strains was 128 but this was not consistent for the RBCs of any one species. All five of the $H$. pylori isolates and one strain of $H$. mustelae tested agglutinated human RBCs of both groups A and B. The type strain of $H$. felis did not agglutinate RBCs of any of the 12 species tested, nor did three other strains of $\boldsymbol{H}$. felis agglutinate RBCs of five different species. 


\section{Inhibition of $\mathrm{HA}$}

Inhibition of $\mathrm{HA}$ after various treatments of RBCs and bacteria to block or destroy potential receptors gave variable results (figure). Four strains of $H$. mustelae with titres against human RBCs and four $H$. mustelae strains with titres against ferret RBCs were examined for HA inhibition. Similarly, six isolates of $H$. pylori that agglutinated human $\mathrm{RBCs}$ and four isolates that agglutinated ferret RBCs were examined for HA inhibition. When bacteria were pre-treated with pronase and heat, $\mathrm{HA}$ of $H$. mustelae was uniformly inhibited with both human and ferret RBCs. Trypsin treatment of bacteria inhibited HA of all $H$. mustelae isolates and human RBCs, and three isolates did not agglutinate ferret RBCs. Heat uniformly prevented HA of $H$. pylori with both ferret and human RBCs. Of the $H$. pylori strains treated with trypsin and pronase, $75 \%$ failed to agglutinate ferret RBCs. HA of human RBCs by $H$. pylori was less affected by these enzymes (figure).

D-Mannose, fetuin and neuraminidase inhibited agglutination of human RBCs with $50 \%$ of the $H$. pylori and $H$. mustelae strains. These three agents were somewhat more effective in inhibiting HA of ferret RBCs by both $H$. mustelae and $H$. pylori. However, none of these compounds was effective in eliminating HA of all strains tested.

\section{Comparison of $H A$ assays}

The results of two different methods for testing HA are shown in table II. In comparing 36 individual HA assays, the results of the slide assay, performed at room temperature and examined microscopically, agreed with the results obtained with the cold slide HA assay. However, the microtitration-plate assay was positive in $26(72 \%)$ of 36 assays on visual observation compared with the cold slide HA assay which was positive in $11(30 \%)$ of 36 tested. Results of $35(97 \%)$ of 36 tests examined microscopically agreed with the cold slide HA assay. The addition of BSA to the buffer did not reduce the number of reactions positive by visual examination.

\section{Discussion}

In our experience, the slide HA assay of Evans et $a l .{ }^{12}$ was difficult to read visually and microscopically, due to the high concentration of RBCs that was $2 \%$ as compared with $0.25 \%$ in the cold slide assay. ${ }^{19}$ However, in our study the results of 36 tests examined microscopically agreed with those of the cold slide HA assay. There were more positive results $(72 \%)$ with the visual microtitration plate $\mathrm{HA}$ assay than with the cold slide assay (30\%). However, more careful examination of the HA pattern by microscopy revealed many $(39 \%)$ false positive results emphasising some inherent inaccuracy in the former method.

Both $H$. mustelae and $H$. pylori agglutinated RBCs of various species in the cold slide HA assay. Similar results have been shown previously with clinical isolates of $H$. pylori. ${ }^{19,20,24,25} H$. mustelae and $H$. pylori had variable patterns of HA with the RBCs of the 12 species examined. Other investigators have also reported variable HA profiles for $H$. pylori with RBCs of different species. However, there is some disagreement with respect to the HA profiles with different $H$. pylori isolates. Several investigators reported that all, or the majority of, their $H$. pylori strains agglutinated human RBCs. ${ }^{19,20,25,26}$ Three HA patterns with human, sheep and rabbit RBCs have been observed with isolates of $H$. pylori. ${ }^{24,27}$ The different results in HA patterns could be due to different assay conditions, different culture conditions, the length of storage of the isolates, serial passage of the bacterium, different receptors and haemagglutinins amongst $H$. pylori isolates.

For example, a novel glycerolipid was found in lipid extracts of human RBCs and human and pig stomach tissues and was recognised by viable $H$. pylori. ${ }^{21}$ Others have also suggested that a soluble haemagglutinin produced by $H$. pylori has a glycolipid receptor. ${ }^{26}$ Another receptor identified for $H$. pylori on RBCs was $\mathrm{N}$-acetyl neuraminylactose, that bound $H$. pylori fibrillar structures. ${ }^{19}$ Recent evidence has suggested that fibrillae were probably not involved in HA of the $H$. pylori strains assayed. ${ }^{24}$ Several studies have implicated receptors for $H$. pylori based solely on HA data. ${ }^{19,24,27}$ Some authors have suggested that $H$. pylori possessed specific sialic acid receptors. Other studies have suggested that different receptors are also present. ${ }^{19,24,25,27-29}$ Indeed, one report stated that strains of $H$. pylori and $H$. mustelae had common haemagglutinins that did not recognise sialic acid receptors. ${ }^{20}$ Since HA was shown to be inhibited by treatment of the bacteria with heat and trypsin, ${ }^{25}$ proteins may also be likely receptors for $H$. pylori.

Our data have indicated that multiple haemagglutinins and receptors may play a role in HA of RBCs by $H$. pylori and $H$. mustelae. The finding that $90.5 \%$ of $21 \mathrm{H}$. mustelae isolates agglutinated human RBCs and $80 \%$ and $85 \%$ of $H$. mustelae agglutinated sheep and guinea-pig RBCs, respectively, implicates a sialic acid receptor. However, blocking assays with fetuin and neuraminidase treatment of human RBCs did not inhibit HA of all isolates, indicating that not all $H$. mustelae and $H$. pylori recognised sialic acid receptors on human RBCs. Blocking of HA by trypsin, heat and pronase suggested that a protein haemagglutinin may be important for $\mathrm{HA}$ of $H$. mustelae. However, it was not uniform among the $H$. mustelae strains with human and ferret RBCs (figure).

We conclude that $H$. mustelae, like $H$. pylori, can agglutinate the RBCs of a variety of species and that multiple receptors and haemagglutinins may be involved. These findings correlate with the close adherence of $H$. mustelae to the gastric mucosa. ${ }^{4} H$. felis, that does not adhere to gastric mucosa, did not agglutinate the RBCs of any species tested. This 
suggests that $H$. felis does not need to adhere to the gastric epithelium to colonise mucus and produce gastritis as observed in stomachs colonised by the adherent $H$. pylori and $H$. mustelae. ${ }^{8,9}$

\section{References}

1. Marshall BJ, Warren JR. Unidentified curved bacilli in stomach of patients with gastritis and peptic ulceration. Lancet 1984; 1: 1311-1315.

2. Marshall BJ, Goodwin CS, Warren JR et al. Prospective doubleblind trial of duodenal ulcer relapse after eradication of Campylobacter pylori. Lancet 1988; 2: 1437-1441.

3. Chen XG, Correa $\mathbf{P}$, Offerhaus $\mathrm{J}$ et al. Ultrastructure of the gastric mucosa harboring Campylobacter-like organisms. Am J Clin Pathol 1986; 86: 575-582.

4. Fox JG, Correa P, Taylor NS et al. Helicobacter mustelaeassociated gastritis in ferrets. An animal model of Helicobacter pylori gastritis in humans. Gastroenterology 1990; 99: $352-361$.

5. O'Rourke J, Lee A, Fox JG. An ultrastructural study of Helicobacter mustelae: evidence of a specific association with gastric mucosa. $J$ Med Microbiol 1992; 36: 420-427.

6. Lee A, Hazell SL, O'Rourke J, Kouprach S. Isolation of a spiral-shaped bacterium from the cat stomach. Infect Immun 1987; 56: 2843-2850.

7. Paster BJ, Lee A, Fox JG et al. Phylogeny of Helicobacter felis sp. nov., Helicobacter mustelae, and related bacteria. Int $J$ Syst Bacteriol 1991; 41: 31-38.

8. Lee A, Fox JG, Otto G, Murphy J. A small animal model of human Helicobacter pylori active chronic gastritis. Gastroenterology 1990; 99: 1315-1323.

9. Fox JG, Lee A, Otto G, Taylor NS, Murphy JC. Helicobacter felis gastritis in gnotobiotic rats: an animal model of Helicobacter pylori gastritis. Infect Immun 1991; 59: 785-791.

10. Lee A, Krakowka S, Fox JG, Otto G, Murphy JC. Helicobacter felis as a cause of gastric lymphoreticular hyperplasia: a confounding factor in canine toxicological studies. $V e t$ Pathol 1992; in press.

11. Beachey EH. Bacterial adherence: adhesin-receptor interactions mediating the attachment of bacteria to mucosal surfaces. $J$ Infect Dis 1981; 143: 325-345.

12. Evans DJ, Evans DG, Young LS, Pitt J. Hemagglutination typing of Escherichia coli: definition of seven hemagglutination types. J Clin Microbiol 1980; 12: 235-242.

13. Angel MA, Burness ATH. The attachment of encephalomyocarditis virus to erythrocytes from several animal species. Virology $1977 ; 83$ : 428-432

14. Sarris AH, Palade GE. The sialoglycoproteins of murine erythrocyte ghosts. A modified periodic acid-schiff stain procedure staining unsubstituted and O-acetylated sialyl residues on glycopeptides. J Biol Chem 1979; 254: 6724-6731.

15. Elyar EH, Madoff MA, Brody OY, Oncley JL. The contribution of sialic acid to the surface charge of the erythrocyte. J Biol Chem 1962; 237: 1992-2000.
This work was supported in part by Public Health Service Grants R01-A125631 and R01-A125590 from the National Institute of Allergy and Infectious Diseases, and Grants P01-CA-28842 and P01-CA-26731 of the National Cancer Institute, National Institutes of Health, US Public Health Service.

16. Shukla AK, Schauer R. Fluorimetric determination of unsubstituted and 9(8)-O-acetylated sialic acids in erythrocyte membranes. Hoppe-Seyler's Z Physiol Chem 1982; 363 255-262.

17. Lund B, Lindberg F, Marklund B-I, Normark S. The PapG protein is the $\alpha$-D-galactopyranosyl- $(1 \rightarrow 4)-\beta$-D-galactopyranose-binding adhesin of uropathogenic Escherichia coli. Proc Natl Acad Sci USA 1987; 84: 5898-5902.

18. Lund B, Marklund B-I, Stromberg N, Lindberg F, Karlsson KA, Normark S. Uropathogenic Escherichia coli can express serologically identical pili of different receptor binding specificities. Mol Microbiol 1988; 2: 255-263.

19. Evans DG, Evans DJ, Moulds JJ, Graham DY. Nacetylneuramenylactose-binding fibrillar hemagglutinin of Campylobacter pylori: a putative colonization factor antigen. Infect Immun 1988; 56: 2896-2906.

20. Morgan DR, Fox JG, Leunk RD. Comparison of isolates of Helicobacter pylori and Helicobacter mustelae. J Clin Microbiol 1991 ; 29 : 395-397.

21. Lingwood CA, Pellizzari A, Law H, Sherman P, Drumm B. Gastric glycerolipid as a receptor for Campylobacter pylori. Lancet 1989; 2: 238-241.

22. Evans DJ, Evans DG, Smith KE, Graham DY. Serum antibody responses to the $\mathrm{N}$-acetylneuraminyllactose-binding hemagglutinin of Campylobacter pylori. Infect Immun 1989; 57 664-667.

23. Arthur M, Johnson CE, Rubin RH et al. Molecular epidemiology of adhesin and hemolysin virulence factors among uropathogenic Escherichia coli. Infect Immun 1989; 57: 303-313.

24. Emödy L, Carlsson $\AA$, Ljungh $\AA$, Wadström T. Mannoseresistant haemagglutination by Campylobacter pylori. Scand J Infect Dis 1988; 20: 353-354.

25. Nakazawa $T$, Ishibashi $M$, Konishi $H$, Takemoto $T$, Shigeeda M, Kochiyama T. Hemagglutination activity of Campylobacter pylori. Infect Immun 1989; 57: 989-991.

26. Robinson J, Goodwin CS, Cooper M, Burke V, Mee BJ Soluble and cell-associated hemagglutinins of Helicobacter (Campylobacter) pylori. J Med Microbiol 1990; 33 277-284.

27. Wadstrom T. Helicobacter pylori hemagglutinins. In: Menge $\mathrm{H}$ et al. (eds) Helicobacter pylori 1990. Berlin, SpringerVerlag. 1990: 19-29.

28. Smith JI, Drumm B, Neumann AW, Policova Z, Sherman PM. In vitro surface properties of the newly recognized gastric pathogen Helicobacter pylori. Infect Immun 1990; 58 3056-3060.

29. Neman-Simha V, Mégraud F. In vitro model for Campylobacter pylori adherence properties. Infect Immun 1988; 56 3329-3333. 